\title{
Erratum to: Range estimates and habitat use of invasive Silver Carp (Hypophthalmichthys molitrix): evidence of sedentary and mobile individuals
}

\author{
Austin R. Prechtel - Alison A. Coulter - Luke Etchison - P. Ryan Jackson • \\ Reuben R. Goforth
}

Published online: 24 August 2017

(C) Springer International Publishing AG 2017

\section{Erratum to: Hydrobiologia DOI 10.1007/s10750-017-3296-y}

The authors wish to correct several unfortunate errors in the aforementioned article. Two sentences in the Results section incorrectly list several values (values listed in tables are correct). Silver Carp 1-, 2-, and 3 -year total ranges are 16.5, 53.6, and $74.2 \mathrm{~km}$ in size respectively, as listed in Table 1 of the published article. The mean location of Silver Carp annual total ranges are at river kilometer (rkm) 506.6 in 2012 and at rkm 509.2 in 2013. Mean location of 2011 annual total ranges are correctly listed in the article and values for these location home ranges are correctly listed in Table 2 of the original publication.

The online version of the original article can be found under doi:10.1007/s10750-017-3296-y.

A. R. Prechtel - A. A. Coulter · R. R. Goforth Department of Forestry and Natural Resources, Purdue University, West Lafayette, IN 47907, USA

A. A. Coulter

Ecological Sciences and Engineering Interdisciplinary Graduate Program, Purdue University, West Lafayette, IN 47907, USA

L. Etchison

Aquatic Biology and Fisheries Center, Department of Biology, Ball State University, Muncie, IN 47306, USA
The results of the Chi squared analysis examining the use of different substrate types is incorrectly characterized in the results section. Silver Carp occurred most often over gravel.

The authors also wish to clarify one sentence in the Results section. The sizes of annual total ranges and annual home ranges at the $95 \%$ isopleth for Silver Carp did not vary among years, therefore, mean values are listed in the article text but are not identified. Silver Carp mean annual total range and annual home range at the $95 \%$ isopleth across the three year study were 35.8 and $31.2 \mathrm{~km}$ respectively. Values for individual years are listed in Table 2 of the aforementioned article.
U.S. Geological Survey, Illinois-Iowa Water Science
Center, Urbana, IL 61801, USA

Present Address:

A. A. Coulter $(\bowtie)$

Center for Fisheries, Aquaculture, and Aquatic Sciences, Southern Illinois University - Carbondale, Life Sciences II, 1125 Lincoln Dr, Carbondale, IL 62901, USA

e-mail: acoulter@siu.edu 